\title{
Low-grade endotoxemia, diet, and gut microbiota - an emphasis on the early events leading to dysfunction of the intestinal epithelial barrier
}

\author{
Kazuhisa Nishizawa* \\ Department of Clinical Laboratory Science, Teikyo University, Japan
}

\begin{abstract}
Low-grade chronic systemic inflammation has been shown to possess the potential to cause obesity, metabolic syndrome, and insulin resistance. Numerous studies have provided insight into the mechanisms by which dietary fat can cause the absorption or permeation of lipopolysaccharides (LPS) present in the gut bacteria into systemic circulation. Additionally, studies have deciphered the vital role of the innate immune system in linking gut microflora and inflammation. Highthroughput sequencing has enabled metagenomic analyses, revealing changes in the gut microbiota composition incurred by high-fat diet. Further insights into the pathophysiological understanding of the interplay between innate immunity, metabolism, and microbiota would help improve therapeutics. This article focuses on the early events leading to the dysfunction of the intestinal epithelial barrier with additional emphasis on the technical problems encountered in in vivo and in vitro experiments. Emerging research results stress the importance of the interaction of LPS with dietary fatty acids and bile acids, as factors that impact the integrity of the gut barrier. Recent findings related to Akkermansia muciniphila and the endocannabinoid system are insightful and indicative of their potential usefulness for therapeutics. Detoxification and tolerance of endotoxin are areas where future developments can be expected. Although not a non-systematic review, this article focuses on the studies that help untangle complicated interplay between microbiology, biochemistry, and immunology.
\end{abstract}

\section{Introduction}

The intestinal commensal microbiota is essential for many host physiological processes and play a major role in the development of many diseases. A major risk factor for metabolic diseases is obesity and the associated metabolic disorders that are characterized by a chronic low-grade inflammation $[1,2]$. This sub-clinical chronic inflammation, along with metabolic diseases contributes to the development of atherosclerosis [3]. This link between metabolic disorders and inflammation has led to an interest in understanding the effects of lipids on the immune system and the impact immune system dynamics has on lipid metabolism [2]. In white adipose tissue (WAT), several distinct inflammatory pathways act in a coordinated manner to secrete proinflammatory cytokines and chemokines, such as (interleukin) IL-6, IL-1 $\beta$ and monocyte chemoattractant protein-1 (MCP-1), respectively. Additionally, WAT secretes adipokines and plays an important role in glucose tolerance and inflammatory responses [4]. In particular, inflamed adipose tissue produces adiponectin that has antiinflammatory effects and decreases lipid accumulation.

The key event triggering low-grade inflammation is the immune response by the innate immune system against various endotoxins, mainly lipopolysaccharide (LPS), a unique component of the gramnegative bacterial cell wall. In most clinical situations, diverse gramnegative bacteria present in the gut microflora are the well-known sources of circulating LPS [5-7].

Toll-like receptors (TLRs) are by far the best-studied family of innate immune receptors). Pattern recognition receptors such as TLRs and nucleotide-binding oligomerization domain proteins (NOD) play a vital role in the detection of microbial infection of induction of inflammation responses. Activation of both TLRs and NODs results in the activation of NF- $\mathrm{kB}$ (nuclear factor $\mathrm{\kappa B}$ ) via downstream signals. TLRs are expressed by professional immune cells and by epithelial cells in various organs [8]. To name but a few, TLR2, as a heterodimer with TLR1 or TLR6, detects bacterial lipopeptides. TLR4 is capable of forming a receptor complex with membrane-associated protein CD14, myeloid differentiation protein 2 (MD2) and/or other adaptor molecules, and detects LPS [8].

In humans, interplay between resident commensal bacteria and a single layer of intestinal epithelial cells is critical in regulating the energy harvesting mechanism from nutrients and in the functioning of the immune system [9]. As discussed in the article, postprandial endotoxemia mainly occurs in a high-fat diet (HFD) dependent manner. Recent studies have established a consensus that low-grade inflammation occurs due to the repeated absorption of LPS from the gut during the digestion of lipids, which in turn could increase the risk of atherosclerosis [5].

Correspondence to: Kazuhisa Nishizawa, Department of Clinical Laboratory Science, Teikyo University, Japan, Tel: +81-3-3964-1211, ext: 46136; E-mail: kazunet@med.teikyo-u.ac.jp

Special Issue: Gut Microbiota and Health - from Bilogy to Clinics Kazuhisa Nishizawa, MD, PhD

Department of Clinical Laboratory Science, Teikyo University School of Medical Technology

E-mail: kazunet@med.teikyo-u.ac.jp

Key words: gTLR4, fatty acids, emulsions, A. muciniphila, intestinal barrier

Received: March 30, 2016; Accepted: April 26, 2016; Published: April 29, 2016 
Within the last decade, numerous reports have linked metaorganismal bioinformatics data to different diseases. This article focuses on the early changes induced by low-grade endotoxemia. So, the following recent review articles could be referred for information related to important diseases, such as obesity or metabolic syndrome [2], diabetes mellitus [10], liver diseases [12], cancer [13,14], cardiovascular diseases [15], neuropsychiatric disorders [16] and a wide range of immunological or inflammatory diseases [6,17]. A growing number of review articles focus on potential therapies aimed at modulating the gut microbiota [18].

Recent years have witnessed an increase in the number of translational studies including adventurous research possibilities. Many of these efforts encounter challenges and limitations resulting in negative results in the light of the hypotheses. In addition to reporting the findings that substantiate the predefined scientific hypothesis, in the present article, an attempt has been made to reflect the authors' thoughts for a relatively small number of papers. Hence, this article should be complemented by ones that are more comprehensive $[5,7,19,20]$. Important topics not covered here include the role of metabolites such as trimethylamine (TMA) that have implications for atherosclerosis and short chain fatty acids (SCFA) that modulate levels of gut hormones involved in glucose and energy homeostasis $[11,15]$.

\section{Endotoxin}

\section{Endotoxin and markers}

Endotoxin is mostly used synonymously with LPS, a major component of the outer membrane of gram-negative bacteria [21,22]. Endotoxins can induce potent responses in a wide range of host species including humans by rapidly inducing cellular biosynthesis and release of pro-inflammatory cytokines such as tumor necrosis factoralpha (TNF- $\alpha$ ) and other bioactive metabolites causing circulatory failure and septic shock. Different species of bacteria produce slightly distinctive forms of LPS with differing toxicity [23]. LPS is released from the bacterial cell wall by shedding or through bacterial lysis [24]. Chemically, LPS is an amphiphilic molecule consisting of hydrophilic polysaccharide components linked to a hydrophobic component called lipid A. Lipid A is the bioactive endotoxin subunit of LPS.

This article mainly focuses on gut-derived LPS, not LPS entering circulation due to infection of exogenous microorganisms. Gut lumen, where many trillions of commensal bacteria reside, has the highest concentrations of LPS [25]. Bacteria and their fragmented component can enter the systemic circulation through several routes including the lymph system [26-28]. Although they do not enter via the hepatic portal system, traumatic injury allows their entry into the systemic circulation. Further, HFD has been reported to facilitate the entry of bacterial products into the systemic circulation at low concentrations.

Depending on the experimental setting, both paracellular permeability and transcellular transport of the gut mucosa are recognized as being important, while the latter is considered more efficient in elevating the levels of LPS in the systemic circulation. This process circumvents hepatic detoxification as LPS is packaged into chylomicrons along with nutrient lipids, which then enter the lymph system for transport to the systemic circulation. In addition to the technical issues concerning measurement (mentioned below), the proinflammatory signal initiation by LPS may depend upon its detailed chemical and physical structure, such as, presence of phosphate groups (that can be removed by alkaline phosphatase), and associated molecules such as bile acids, fatty acids (FAs), membranes or lipoproteins.

Presence of LPS in human serum is primarily measured using a Limulus amebocyte lysate (LAL) assay, which has technical drawbacks due to the presence of interfering compounds in the serum $[29,30]$. LPS is quantified either in terms of its weight (ng) or in endotoxin units (EU). The term EU reflects the endotoxic activity of the mixture of LPS molecules present in the sample. According to the international WHO Standard, 1 EU is defined as the biological activity measured by the endotoxin test that was induced by $120 \mathrm{pg}$ of LPS from Escherichia coli O113:H10:K [30]. However, the absolute values of LPS measured in the plasma showed large variations among studies, probably because of the higher sensitivity of LAL assay towards pre-treatment procedures. The mean values measured in healthy subjects ranged from 0.15 to $61 \mathrm{EU} / \mathrm{mL}$ (median $0.32 \mathrm{EU} / \mathrm{mL}$ ) or from 0.5 to $65 \mathrm{pg} / \mathrm{mL}$. However, for diluted samples, the mean value was $12.1 \mathrm{EU} / \mathrm{mL}$, which was far higher than that obtained for undiluted samples [30]. Thus, for patients with low-grade endotoxemia, absolute LPS levels are rather unreliable, suggesting the relative importance of nonparametric statistical analysis in these cases. An LPS ELISA kit assay was recently used by Gnauck et al. [31] instead of the LAL assay, after checking with a recovery test in which a known dose of LPS was added to serum samples [31].

LPS-binding protein (LBP) recognizes LPS and transfers it to CD14, thereby enhancing host cell stimulation. LBP can also transfer LPS to HDL particles in vitro [32,33]. LBP, an acute-phase protein produced mainly by the liver, binds to the lipid A portion of LPS and enhances its ability to activate immune cells. LBP has the unique ability to recognize and bind LPS multimers or LPS contained in fat micelles, initiating its monomerization. Immune receptors and proteins such as CD14, TLR4 and MD-2 recognize and bind to LPS monomers and initiate an immune response [32]. Lamping et al. [33] presented a bimodal effect for LBP. In vitro, addition of recombinant LBP (mLBP) at $<1 \mu \mathrm{g} / \mathrm{mL}$ resulted in increased secretion of TNF- $\alpha$ upon LPS challenge. However, higher concentrations of mLBP $(10 \mu \mathrm{g} / \mathrm{mL})$ in the acute phase stimulated decreased secretion of TNF- $\alpha$ in response to the LPS challenge, relative to the case with $0.1 \mu \mathrm{g} / \mathrm{mL} \mathrm{mLBP}$. Thus, acute phase LBP is likely to have a protective effect against LPS and bacterial infections. LBP is increasingly being used as a relevant marker for metabolic endotoxemia in clinical and rodent studies, although systemic inflammation should cause non-specific increases of acutephase proteins including LBP. Results from the studies conducted by Laugerette [34], indicated correlation between plasma LBP and plasma IL-6 $(\mathrm{r}=0.905)$ in individual mice (fed on palm oil-enriched diet, in this case).

LPS cannot directly bind to TLR4/MD-2 but must be presented by CD14 [23]. CD14 is multifunctional protein with specificity for LPS and together with TLR4 forms a complex that activates the innate immunity system. CD14 exists in two forms, namely, a membranebound glycoprotien form (mCD14) that act on the surface of monocytes, macrophages and poymorphonuclear leukocytes, and a circulating soluble form (sCD14) [35]. sCD14 has suppressing effects on endotoxin activity by facilitating the transfer of LPS micelles to HDL, and further to phosphatidylcholine membranes, assisting their transport to the liver, and thereby driving detoxification [36,37]. A dual stimulatory and inhibitory mechanism of sCD14 and LBP has been reviewed by Kitchens and Thompson [38]. Broadly, LBP appears to reflect inflammation levels like other acute-phase proteins, but sCD14 appears to have a protective action; high sCD14 may counteract progress of inflammation in the presence of LPS. 
Other potential markers of bacterial exposure include bacterial FAs. In a randomized, controlled trial with humans, Umoh et al. [39] tested a Mediterranean diet and the healthy diet [40] over 6 months. No change was detected in serum LBP concentrations with either diet intervention, relative to the control diet group. However, across individuals, LBP showed a positive correlation with C-reactive protein (CRP) and a negative correlation with carotenoids. Importantly, a decrease in the concentration of branched-chain bacterial fatty acids (BFAs) was observed in both diet groups. Thus, BFAs, commonly present in gram-positive and gram-negative bacteria, could serve as a promising direct marker to detect the extent of bacterial exposure.

\section{Diet and endotoxin}

In response to the intake of HFD, LPS can diffuse from the gut to the blood stream either by direct diffusion mediated by paracellular permeability or through absorption by enterocytes during chylomicron secretion [26-28].

Cani et al. [41] examined whether LPS could be a physiological regulating factor dependent on the feeding status. Mice fed a HFD (72\% fat, corn oil and lard) for 4-weeks showed a constant increase in plasma endotoxin concentration, whereas in control groups the endotoxin concentration was elevated only in the feeding hours. In HFD-fed mice, several bacteria belonging to Eubacterium rectale/Clostridium coccoides group, Bifidobacterium and Bacteroides-like mouse intestinal bacteria were significantly reduced. HFD increased fasting glucose and insulin resistance, along with weight gain of overall-body, liver, visceral, and subcutaneous adipose tissue. Infiltration of macrophages was seen in the adipose tissue. Additionally, in the liver and visceral adipose tissue increased levels of mRNA was detected for TNF- $\alpha$, IL-1 and IL-6. Similar effects were reproduced by subcutaneous infusion of LPS, retaining similar concentration of circulating LPS as in HFD-fed mice. These effects were reported to be mediated by TLR4 and CD14.

According to Cani et al. [41], a 72\% HFD increased endotoxemia 2.7 -fold when compared with control fed mice. This increase was only 1.4 -fold when the mice were fed with a $40 \%$ HFD. If these results were assumed transferrable to humans where ethical issues would limit dietary fat intake, such a difference would lead to statistical challenges. Technically, in the study conducted by Cani et al. [41], the plasma concentration of LPS was determined using LAL assay. Additionally, levels of LBP and other relevant parameters were not reported.

Erridge et al. [42] demonstrated that, in healthy humans, postprandial plasma endotoxin concentrations increased $18 \%$ on an average after a HFD ( $380 \mathrm{kcal}$ from fat, $42 \%$ of total energy) relative to the fasted state. In order to validate the result obtained with LAL assay, the authors used endotoxin neutralization capacity assays that measured the depletion (reduction) of endotoxin-neutralizing substances in the plasma; the reduction of such substances suggested prior exposure to endotoxin.

Ghanim et al. [43] showed that compared to the American Heart Association (AHA)-recommended meal, $910 \mathrm{kcal}$ containing high-fat, high-carbohydrate meal, increased postprandial plasma LPS by $47 \%$ in humans, at 1,2 and $3 \mathrm{hr}$ after the meal, with an associated increase of plasma LBP by $34 \%$. This increase was accompanied by an increase in the mRNA expression of TLR2 and TLR4 in blood mononuclear cells.

sCD14 and plasma LBP are considered as relevant markers that reflect long-term exposure to endotoxin rather than the measurement of endotoxin itself. Such an estimation is relevant because of the long half-lives of sCD14 and LBP ranging from $24-48 \mathrm{~h}$, which is much longer when compared to that of endotoxin $<8 \mathrm{~min}$ in mice to a maximum of $3 \mathrm{~h}$ in humans $[34,44]$.

Laugerette et al. [34] demonstrated that a synergistic proinflammatory effect between LPS and FAs. The authors subjected mice for 8 weeks on a diet enriched with milk fat, palm oil, rapeseed oil or sunflower oil. Major FA constituents of palm oil were 16:0 (45\%) and 18:1 n-9 (37\%), with the content $18: 3$ n-3 being low $(0.5 \%)$, whereas those of rapeseed oil were 18:1 (59\%) and 18:2 (23\%), with 18:3 n-3 being relatively rich $(9.7 \%)$. Intriguingly, palm oil-enriched diet resulted in inducing the highest inflammation in plasma (based on IL-6) and adipose tissue (IL-1 $\beta$ and TLR4) compared to the other diets. Rapeseed oil-based diet resulted in lower inflammation despite the elevated endotoxemia, probably mediated by higher levels of sCD14, suggesting a protective role for sCD14. It appears that not only LPS from the gut, but effects of dietary lipid on endotoxin receptors, transporters and CD14 activation seems to play an important role in the subsequent immune activation. Individual mice fed on palm oilenriched diet showed correlation between plasma LBP and IL- 6 ( $r=$ 0.905), although LBP increase may be secondary to the inflammation. These observations suggest the presence of synergistic action between FAs and LPS; apart from the levels of LPS present in the circulation, the saturation levels of FAs simultaneously absorbed from the gut lumen also exert an impact on the activation of endotoxin receptors.

Laugerette et al. [45] further demonstrated that healthy human subjects overfed for 8 weeks $(+760 \mathrm{kcal} /$ day), showed increased levels of LBP/sCD14 suggesting that the inflammation setup during the initial phase of weight gain is linked to the relative variations of LBP and SCD14 [45].

These studies have generated a consensus that dietary fat could increase the concentration of circulating LPS and this resultant postprandial endotoxemia could lead to low-grade systemic inflammation, which has been implicated in metabolic disorders.

\section{Translocation of LPS from gut to blood}

In the early phase of postprandial endotoxemia, LPS present in the gut lumen enters into the lymphatic system, and eventually into the blood stream through transcellular transport. Chylomicron, a lipoprotein that transports triglyceride form the gut to adipose tissues, is an important carrier of LPS in this phase. Prolonged HFD and/or systemic inflammation leads to dysfunction of tight junction barriers, resulting in a leaky gut. This view assumes the transition from transcellular permeation to paracellular permeation by taking into consideration the relationship with various factors. However, emulsified FAs present in the diet are likely to cause dysfunction of tight junction leading directly to a leaky gut. Here, a few recent studies related to endotoxin detoxification and tolerance has been discussed briefly.

Transcellular epithelial transport of LPS - early events: In order to study the early events related to the transcellular epithelial transport of LPS, Tomita et al. [46] used a diffusion chamber system with colonic epithelial tissues isolated from normal rats. FITC (fluorescein isothiocyanate)-LPS applied at a concentration of 100 $\mathrm{ng} / \mathrm{mL}$ showed higher permeability from mucosal to serosal ( $\mathrm{M}$ to $\mathrm{S}$ ) direction, compared to the $\mathrm{S}$ to $\mathrm{M}$ direction. Permeability towards both directions was dependent on temperature, suggesting the involvement of an enzymatic and/or an energy-dependent process. Compared to normal rats, an intraperitoneal (i.p.) injection of LPS, $4 \mathrm{~h}$ before the 
experiment did not detect any significant difference in transepithelial conductance, suggesting that the paracellular route including tight junctions remained unchanged by the pre-exposure. Thus, the permeability of FITC-LPS is at least in part mediated by a special transcellular transport system, other than tight junctions. Transport in both directions showed dependency on CD14 and TLR4. Although this study did not test the effects of dietary fat, efforts including this study have established the involvement of a TLR4-mediated, energydependent transcellular transport mechanism for LPS.

Mani et al. [47] compared the pigs fed with control meal and meals enriched in, fish oil, vegetable oil, and coconut oil. Postprandial (1-5 hrs) serum endotoxin increased in pigs fed coconut oil, which was relatively rich in saturated FAs, whereas fish oil-enriched meal did not increase the endotoxin. The authors also performed ex vivo analyses in which normal pig ileum samples were mounted into modified Ussing chambers and treated with the different oils for $2 \mathrm{hrs}$. Fish oil and cod liver oil reduced FITC-LPS permeability but coconut oil increased the permeability. Lipid raft-modifier methyl- $\beta$-cyclodextran treatment greatly compromised FITC-LPS transport. Notably, transepithelial resistance unchanged through the experiment, suggesting that FITCLPS permeability is mainly accounted for by raft-mediated endocytosis.

Thus, Mani et al. [47] showed a quick effect of saturated FAs-rich oil (within a few hours) on LPS permeation. It is interesting that, in such an early phase of postprandial period, LPS permeation occurred in a manner dependent on particular types of FAs and on some functions of lipid raft. A merit of this study was that relatively usual diets were used, compared to experiments using emulsified FAs. Although it still remains unclear whether differential modulations of lipid raft functions by different FAs is the key issue, this study suggested that the rate of raft-mediated LPS absorption is likely to be sensitive to the proportion of saturated FAs in diet.

Dietary fat is absorbed into enterocyte, and incorporated as triglycerides into chylomicron. Chylomicrons and their remnants are transported though mesenteric lymph before entering the blood stream and being cleared in liver and other organs/tissues or transported to adipose tissues. Chylomicrons have high affinity for LPS $[48,49]$.

Ghoshal et al. [27] showed in mice that ingestion of long-chain triglycerides (triolein) for $6 \mathrm{hr}$ causes an increase in plasma LPS, the increase being mainly associated with the chylomicron remnant fraction. Chylomicron remnants are particles corresponding to chylomicrons from which triglycerides have been transferred to adipose tissues. Triolein ingestion promoted LPS absorption into mesenteric lymph nodes in a manner dependent on chylomicron formation. They further showed that chylomicron formation enhances secretion of LPS from basolateral side of Caco-2 cells.

As discussed in [27], although some LPS acquired by intestinal epithelial cells remains on the cell membrane [50], significant amounts of LPS are internalized and directed to the Golgi, where the most TLR4 resides [51].

Laugerette et al. [28] focused on the effect of various structures (oilin-water emulsion, free oil or dispersion) and compositions of dietary fat on the kinetics of lipid and LPS absorption. In humans, postprandial LPS and sCD14 increased after $1 \mathrm{hr}$ (with increases over postprandial 4 $\mathrm{hr}$ ) of mixed meal containing dispersed lipids (LPS was not added). Using rats, they also showed that emulsified oil, which is a fine emulsion of sunflower oil in saline with lecithin at $35 \mathrm{mg} / \mathrm{ml}$ emulsion, enhances postprandial endotoxemia compared to non-emulsified oil. Strikingly, their Caco-2 experiments showed that, compared to incubation with LPS (at $1 \mathrm{micro} \mathrm{g} / \mathrm{ml}$ ) alone that showed negligible levels of absorption rate, dramatically higher levels of LPS absorption rate were observed when lipid micelles containing oleic acid at $0.5 \mathrm{mM}$ or $1.5 \mathrm{mM}$ were added. Of note, the micelles contained taurocholate, lecithin and cholesterol. LPS absorption was efficient when LPS present in the apical side (i.e., the side facing the intestinal lumen) were contained in emulsified structures, likely because this enlarges the surface area aiding digestion and/or when phospholipids that act detergent that are known to facilitate absorption when contained in the dietary fat.

Thus, besides the amount of FAs, saturation levels and the degree of emulsification are important for absorption of LPS from the gut. It would be interesting to ask whether physiological emulsions that are mainly made up of bile acids could be safer and limit the absorption rate of LPS, compared to FA-rich emulsions.

Intestinal tight junction: Tight junction is an important element of the intestinal epithelial barrier. Invasion of substances, such as LPS present in the lumen, through tight junctions is referred to as paracellular invasion. The structure of tight junction is dynamic and can be disrupted by inflammation [52,53]. Cytokines including TNF- $\gamma$, TNF- $\alpha$ and IL- 6 increase the intestinal permeability by increasing myosin light chain kinase, phosphorylated myosin light chain (pMLC), and expression of claudin-2 (a pore forming type of protein belonging to the claudin family) [53]. Cytoplasmic sequestration (internalization) of the major constituents of tight junctions, such as occludin, claudins and zonula occludens- 1 causes disruption of the barrier function $[53,54]$.

Brun et al. [55] reported that genetically obese mice (ob/ob and $d b / d b$ mice) had lower intestinal resistance, modified distribution of occludin and zonula occludens-1 (ZO-1) in the intestinal mucosa and higher levels of portal endotoxemia, compared to control mice [55]. de La Serre et al. [56] showed that HFD-induced obesity was associated with inflammation of the gut, increased permeability leading to occludin internalization and an increase in pMLC [56].

Guo-Ma [57] examined the effects of inflammatory bowel diseases (IBDs)-relevant levels of circulating LPS on intestinal epithelial barrier [57]. IBDs exhibit circulating levels of LPS that are slightly higher than those of obesity and metabolic syndrome. Nevertheless, this study might shed light on the effects of milder endotoxemia. Based on transepithelial conductance and inulin flux measurements, they showed that LPS at $0.3 \mathrm{ng} / \mathrm{mL}$ or above caused an increase in permeability in Caco-2 cells (filter-grown, monolayers). This flux increase occurred 4 days after the addition of LPS. Similar effects were shown by LPS in other cell lines (NCM460, a human colon mucosal epithelial cell line, and T84, a colonic adenocarcinoma cell line). Removal of LPS resulted in restoration of resistance in Caco- 2 within 2 days. The effect on Caco-2 was pronounced when LPS was added to the basolateral side, while the addition to the apical side yielded negligible effects. Additionally, by using siRNA-induced silencing of TLR4 expression together with TAK-242 (inhibitor of TLR4 signaling), they proved that the above results seen in Caco-2 was mediated by TLR4. In vivo, in mice, administration of a stable concentration of LPS $(0.4-0.5 \mathrm{ng} / \mathrm{mL}$, while control mice had $0.017 \mathrm{~nm} / \mathrm{mL}$ ) showed increased permeation of texas-Red-dextran $(10 \mathrm{kDa})$ at day 5 , suggesting that clinically relevant concentrations of LPS could increase intestinal permeability. Experiments with knockout mice demonstrated the involvement of TLR4 in this process. In the above experiments, both, the in vitro and in vivo phenomenon was mediated by LPS-induced expression of 
TLR4 and CD14, which was a relatively slow process (several days). The authors further proved that at physiological levels, LPS could initiate a TLR4 signal transduction cascade within epithelial cells, leading to the activation of focal adhesion kinase (FAK) over a period of 3-5 days [58]. FAK expression and signaling has been shown to be important for promoting cell adhesion, apoptosis, migration, and proliferation in a variety of cell types [59].

Other pathophysiological and immunological factors affecting intestinal barrier: Recently, excellent review articles have summarized data on several non-dietary factors that affect intestinal permeability [60]. Such factors include stimulation via sympathetic nervous system, corticotropin-releasing hormone (that induces expression of TLR4), exercise-induced heat stress, and alcohol consumption.

Several studies have shown that mature human intestinal epithelial cells (IECs) show hyporesponsiveness to LPS, and this is likely based on downregulation of TLR4/MD2 complex [61]. Exposure of murine neonatal IEC to LPS during vaginal delivery induces TLR4 pathway activation followed by a decrease in interleukin-1 receptor-associated kinase 1 (IRAK-1) protein levels, leading to the acquisition of tolerance to LPS $[23,62]$.

The HFD-induced increase in barrier permeability is partly accounted for by the action of IFN- $\gamma$ and IL- $1 \beta$, whereas IL- 22 and regulatory $\mathrm{T}$ cells (Tregs) exerted protective effects [7]. In the distal small bowel of mice and rats, prolonged HFD-feeding induced NF- $\kappa B$ expression and an increase in TNF- $\alpha$ and IL-1 $\beta$. Typically, the increase was evident after 2 weeks rather than after 1 week, suggesting the need for a relatively long time course for the expression of pro-inflammatory changes [7]. Effects of prolonged HFD-feeding on TLRs signaling, nucleotide-binding oligomerization domain (NOD)-like receptors (NLRs), innate lymphoid cells such as, $\gamma \delta \mathrm{T}$ cells, eosinophils, and macrophages, and on adaptive immune system have been discussed in detail elsewhere [7].

\section{LPS clearance}

Detoxification of LPS by alkaline phosphatase is discussed in section 5 . Here, the mechanisms for LPS clearance from the circulation are briefly discussed. In both in vivo and in vitro experiments, LPS was rapidly bound to lipoproteins. Lipoprotein-bound LPS is less proinflammatory and is cleared more slowly than free LPS, possibly because of the sequestration of lipid A moiety within the lipoprotein micelle [63-65].

Liver was identified as the primary site of LPS clearance in early studies [55,66]. Acyloxyacyl hydrolase (AOAH), an enzyme present in Kupffer cells is highly capable of detoxifying LPS. This enzyme is also expressed by non-hepatic macrophages $[67,68]$. Hepatocytes are reported to participate in LPS clearance $[69,70]$. A few prominent findings are discussed here.

Deng et al. [68] used tissue-specific TLR4-knockout mice (myeloid cells and hepatocytes) and showed that after cecal ligation and puncture (CLP), phagocytosis by myeloid cells (macrophages and neutrophils) was required for the rapid clearance of bacteria and LPS in the absence of antibiotics. TLR4 was essential for macrophage- and neutrophilmediated phagocytic bacterial clearance. However, in the presence of antibiotics, TLR4-mediated LPS clearance by hepatocytes was important to prevent low levels of LPS that could cause inflammation. These results imply that the main mechanism for LPS clearance differed in a manner that was dependent on the level of LPS present in the plasma.
Imajo et al. [71] demonstrated that in mice, although normal liver is largely non-responsive to normal postprandial levels of LPS from portal vein, overexpression of CD14 in Kupffer cells triggered progression towards nonalcoholic steatohepatitis via hyper-responsivity to lowdose LPS. Intriguingly, the upregulation of CD14 in Kupffer cells was observed in HFD-induced steatosis mice, but not in control mice. Strikingly, treatment with leptin in control mice caused increased hepatic expression of CD14 via STAT3 (signal transducer and activator of transcription 3) signaling, resulting in hyper-responsivity to lowdose LPS without steatosis. This was an unexpected result taking into consideration that leptin was generally known to be a hormone suppressing appetite and improving insulin sensitivity. This study suggests that immune response against LPS is intricately controlled by factors involving hormones.

In the study conducted by Imajo et al. [71], when the levels of bacteria were high as in sepsis, TLR4 supported both, the hepatic clearance of postprandial levels of LPS, and macrophage- and neutrophil-mediated phagocytic clearance of LPS. However, certain reports indicate that hepatocytes develop tolerance towards the uptake of LPS, which is mediated by previous exposure to low-levels of LPS [72]. What complicates the matter is the increased sensitivity to LPS seen in hepatic stellate cells isolated from leptin deficient mice $(o b / o b)$ when compared to normal mice [55]. Thus, regulation of tolerance and sensitization against LPS seems important in hepatic response to longterm exposure of low levels of LPS. It is tempting to envisage that subtle regulations of sensitivity to LPS could be possible through hormones in adipose tissue, intestinal cells, and macrophages.

\section{Fatty acids}

Dietary triacylglycerol is hydrolyzed in the gastrointestinal tract and yields FAs. Diets rich in saturated FAs have been implicated in the development of metabolic diseases associated with dyslipidemia, insulin resistance, and atherosclerosis [73,74]. Studies related to FAs, general proinflammatory role of saturated FA, and benefits of n-3 ( $\omega$ 3) polyunsaturated fatty acids (PUFAs) have been well documented $[73,74]$.

n-3 PUFAs are preferred activators of peroxisome proliferatoractivated receptor (PPAR) $-\gamma$ and PPAR- $\alpha$, explaining their effects on fat mass reduction [75]. n-3 PUFAs act as competitive inhibitors of arachidonic acids on cyclooxygenase which produces proinflammatory eicosanoids. Although partly attributable to the competition with arachidonic acids, n-3 PUFA-rich diet can dramatically modulate the levels of arachidonic acids-derived endocannabinoids, such as 2-arachidonylglycerol (2-AG) in humans and rodents [7,77]. Further, recent discoveries revealing the presence of $G$ protein-coupled receptors (GPCRs) for FAs, indicate another level of FA functioning. However, given that saturated FAs enable formation of lipid raft on cell surface and that they themselves are precursors of signaling molecules, it is likely that they exert their effects at multiple levels, some being physicochemical, and some more specific. Understanding the relative significance of the diverse functional levels of FAs require further investigation $[73,74]$.

\section{FAs emulsion can disrupt the intestinal epithelial barrier}

A couple of studies on FAs' effect on intestinal barrier, which seem somewhat unappreciated, are discussed. FAs can enhance drug absorption in intestine as shown, for example, in the experiment using mannitol in the Caco-2 cell model [78]. Strikingly, Kvietys et al. [79] showed that emulsions made up of 10-40 mM oleic acid (16:1) 
and $20 \mathrm{mM}$ bile salt cause disruption of both the jejunal mucosa in anesthetized rats in vivo and in intestinal epithelial cells (IEC-18) in vitro, based on the measurement using ${ }^{51} \mathrm{Cr}$-EDTA [79]. AspenströmFagerlund et al. [80] showed that emulsions of FAs either with oleic acid or docosahexaenoic acid (C22:6 n-3, DHA) have potential to disrupt the intestinal epithelium barrier. Thus, epithelial injury may be a relatively common event during digestion and absorption of diet [79]. This finding was striking in that, despite its well-known benefit to our health, DHA emulsions can compromise the integrity of the intestinal epithelium, making the gut leaky. It is important to note that restitution, or rapid reepithelialization of denuded basal lumina (on scales of hours), is likely to play an important role in repairing the superficial defects in the epithelial lining incurred during the normal course of digestion and absorption of food [81].

Recent notable studies include those on butyrate, a SCFA produced by Gram-positive anaerobic bacteria, as a product of fermentation of non-digestible carbohydrate [82]. Butyrate tends to reduce inflammation through binding to GPR43 [74]. Butyrate also has anti-obesity effects by stimulating the expression of angiopoietin-like protein-4 (ANGPTL-4) [81].

\section{FA and inflammation}

In animal models and clinical trials, long-chain n-3 PUFAs, such as eicosapentaenoic acid (C20:5 n-3, EPA) and DHA exerted beneficial effects in the treatment of IBDs [74]. In an in vivo inflammatory model, piglets after $4 \mathrm{~h}$ postinjection with LPS and supplementation with fish oil showed enrichment of EPA, DHA, and total (n-3) PUFA in intestinal mucosa, inhibition of TLR4 and NOD2 signaling pathways, and a concomitant improvement of intestinal integrity (increases in the number of tight junction proteins) [84]. Of note, NOD1 and NOD2 can be indirectly activated by LPS through TLR4 and TNF- $\alpha$.

Next, the focus was to find if FAs could bind TLR4. Lee et al. [85] presented data indicating reciprocal modulation of TLR4 activation by saturated and PUFAs in transfection experiments conducted on 293 T cells. This confirmed the trend that overall saturated FAs favored TLR4 stimulation. [86] However, Erridge [87] reported that saturated FAs lacked the ability to stimulate TLRs directly, and emphasized the importance of measures needed to exclude contaminating LPS, and lipopeptides from experimental systems [88]. Schaeffler et al. [89] observed FA-induced induction of TLR4/NF- $\mathrm{B}$ pathway in adipocytes, but this effect was caused by an endogenous ligand since FAs were shown not to bind directly to TLR4/MD-2 [89]. Pal et al. [90] reported fetuin A, a secretory glycoprotein of the liver, as an endogenous ligand of TLR4 mediating the above mentioned FAs stimulation of TLR4. However, further analyses on fetuin A would be beneficial as Jialal et al [91] reports no significant correlation between monocyte TLR4 and plasma fetuin A. These results suggests that in humans, fetuin A likely mediates the effects of FAs, but it might induce insulin resistance by mechanisms other than through the activation of TLR4 [91], although fetuin A showed a strong correlation with free FAs. Further complications of saturated FAs arise due to their role as precursors. Saturated FAs are used for the biosynthesis of ceramide or other functional lipids, thereby permitting or enhancing TLR4 activity [92]. FAs also modify physical properties of the bilayer and modulate raft and signaling activities of various signaling molecules [93]. Further, FA receptors have been characterized recently and a few of them are presently reviewed.

Many studies have focused on GPCRs that could recognize FAs. To name but a few, Hirasawa et al. [94] showed that GPR120, abundantly expressed in intestine, functions as a receptor for unsaturated longchain Fas. Stimulation of GPR120 by FAs promoted the secretion of glucagon-like peptide-1 (GLP-1) both, in vitro and in vivo, and increased the levels of insulin in the circulation. GPR120 is expressed in adipose tissue and proinflammatory macrophages. Additionally, n-3 PUFAs (DHA and EPA), the major ingredients in fish oil, exerted potent anti-inflammatory effects through GPR120 [95]. Stimulation of GPR120 with n-3 PUFAs or a chemical agonist causes broad antiinflammatory effects in monocytic RAW 264.7 cells and in primary intraperitoneal macrophages. In human, loss-of-function GPR120 gene variants caused increased risk of obesity, insulin resistance, and its sequelae [96]. These findings are consistent with the beneficial effect of fish oil. i.c.v. administration of n-3 PUFAs into obese rats resulted in local anti-inflammatory effects, through the hypothalamic GPR120 receptor [97]. Anbazhagan et al. [98] showed that, stimulation of GPR120 in Caco-2 cells inhibits NF- $\mathrm{kB}$ activation in a $\beta$-arrestin-2 dependent manner. Similar effects of PUFA HFD was observed in wild type mice by Bjursell et al. [99] using a GPR120-deficient mouse strain, leading the authors to conclude that GPR120 appears to be dispensable for the improved metabolic profile associated with the intake of a diet enriched in n-3 PUFAs. These results imply that n-3 PUFA could exert beneficial effects through many levels, relative significances of which have yet to be studied.

\section{Microbiota}

The diverse gut microbiota, its relevance to our health and associated clinical problems has been summarized in various reviews including Marchesi et al. [100]. In the following, a few studies related to the intestinal barrier have been reviewed briefly.

\section{Diet, metabolic diseases and microbiota}

Numerous studies have shown the impact of diet and its role in the modulation of gut microbiota [100,101]. Large variations are observed in the composition of the gut microbiota associated with decreased microbial diversity in Western populations as compared with people from rural Africa [102]. LeChatelier et al. [103] described the association of obesity with low bacterial richness. The bacterial richness could be increased by restriction energy in diet. However, in individuals with lower gene richness, this dietary intervention was found to be less efficient for inflammatory variables [104,105].

In several studies, large alterations in gut microbiota were found to be associated with switching to HFD, including a decrease in Bacteroidetes and an increase in both Firmicutes and Proteobacteria $[11,105]$. A cross-sectional analysis carried out by Wu et al. [106] using $16 \mathrm{~S}$ rDNA sequencing and shotgun metagenomics of fecal samples from 98 individuals found that enterotypes were associated with longterm diets, particularly protein and animal fat (Bacteroides) versus carbohydrates (Prevotella). A significantly higher ratio of Firmicutes/ Bacteroides was reported in type 2 diabetes compared to lean controls and obese subjects [107]. Although discussing the influence of nondietary factors on gut microbiota is beyond the scope of this review, it is worth mentioning that stress alters gut motility and mucin production, thereby altering the habitat of resident bacteria [108].

A number of studies have established the effect of HFD on microbiome composition, yet, insight into how such difference are linked to human health still remains to be explained. The importance of Firmicutes/Bacteroides ratio itself is a matter of debate as LPS is derived from the latter. Such changes might merely indicate as to how microbiome could form an ecosystem and rapidly adapt to the change 
in food. Nonetheless, there are several examples conforming positive results related to different probiotics strains, prebiotics treatments, and, although mostly in animals, fecal (gut microbiota) transplantation [100].

Commensal bacteria residing in the gut exert a significant impact on the intestinal barrier in many ways by varied mechanisms and are discussed in the next section. Many pathogenic bacteria including, Helicobacter pylori, E. coli, Staphylococcus aureus, Pseudomonas aeruginosa, and Campylobacter jejuni alter or disassemble tight junctions by increasing inflammation, thereby making the gut leaky [109].

\section{Linkage of the effect of diet to microbiota, barrier and inflammation}

Colonization of germ-free (GF) mice with contents obtained from the cecum of conventionally raised mice resulted in a $60 \%$ increase of body fat content and insulin resistance in the originally GF mice [110]. Additionally, the microbiota promoted absorption of monosaccharides form the gut lumen, and the microbiota-induced deposition of triglyceride in adipocytes required suppression of Fiaf (fasting-induced adipocyte factor, later referred to as ANGPTL-4), a circulating lipoprotein lipase inhibitor.

In the quest for knowledge related to beneficial probiotic interventions, studies using animal models and cell culture systems have shown that lactobacilli and bifidobacteria are able to counteract increased paracellular permeability evoked by cytokines, chemicals, infections, or stress [111,112]. Administration of prebiotics (oligofructose) in ob/ob mice increased Bifidobacterium spp. and Lactobacillus spp. [113]. This increase was in turn associated with a decrease in inflammation and oxidative stress markers. Additionally, it improved tight junction integrity and thereby lowered intestinal permeability. In a mouse model representing necrotizing enterocolitis, administration of a probiotic composed of Bifidobacterium infantis stabilized claudins at tight junctions and prevented dysfunction of the intestinal barrier [114]. These findings are consistent with the results that HFD induced alterations in the gut microbiota leading to reduction in the population of bifidobacteria [26]. In the near future, molecular mechanisms behind these finding might be deciphered, although these effects would likely involve complex interactions of the immune system [7].

It is difficult to address within a single study, the linkage of diet to microbiota, inflammation, and metabolism. However, one such endeavor was made by Caesar et al. [115], wherein mice were fed with lard for 11 weeks. At the end of the experiment, these mice showed an increase in TLR activation and WAT inflammation with reduced insulin sensitivity compared to mice fed on fish oil. The phenotypic differences between the two groups were partly attributed to the difference in the microbiota composition, based on the analyses using GF mice. Analyses of cecal microbiota transplant showed that the microbiota from the mice fed with fish oil counteracted adiposity and inflammation in mice subsequently fed with lard. The chemokine CCL2 was found to contribute to the microbiota-induced WAT inflammation in lard-fed mice. $16 \mathrm{~S}$ rRNA sequencing indicated $24 \%$ variability in the microbiota composition, which was explained by the difference in the fat source. This result was remarkable given the variance among individual mice of the same group. (Core microbiome and betweenindividual variances in humans have been reported [116].) SCFA levels were largely similar in cecal samples between the lard-fed mice and fish oil-fed mice. Serum from mice fed with lard had higher levels of ligands for TLR2 and TLR4. Sequence profiling of bacteria in blood (vena cava) and WAT did not show significant difference between mice fed on lard or fish oil. Thus, it is likely that the gut microbiota stimulates inflammation through their pro-inflammatory molecules rather than by translocation of the bacteria themselves. This report also revealed that mice fed with fish oil had increased number of bacteria belonging to the genera Lactobacillus and Akkermansia muciniphila.

Studies on A. muciniphila have provided important insights on the effect of microbiota on the intestinal barrier. A. muciniphila is a mucin-degrading bacterium that resides in the mucus layer [117]. A HFD regimen reduced the abundance of Bifidobacterium spp. and A. muciniphila $[41,118]$. In an in vivo mice model, with HFD, metabolic disorders progressively developed with time over the tested period (12 weeks) [119]. The abundance of Bifidobacterium spp. and A. muciniphila, were strongly associated with markers of lipid metabolism (FA oxidation and fat browning) and negatively associated with inflammation in adipose tissue, circulating glucose, leptin, triglycerides and insulin. Interestingly, Bilophila wadsworthia showed an opposite trend [119]. Increased abundance of B. wadsworthia was associated with fat feeding and inflammation [120].

In mice with diet-induced obesity, oral administration of $A$. muciniphila reduced fat mass gain and WAT macrophage infiltration and improved the gut barrier function (restoration of mucus thickness thinned by HFD) and glucose metabolism [118].

Elevated levels of arachidonic acid-derived endocannabinoids (eCBs) have been implicated in obesity $[73,121]$. eCBs are generated on demand from phospholipids of cell membranes. The eCB system is likely a key signaling system in the energy homeostasis and metabolism. eCBs are likely to account for at least part of the beneficial effects of A. muciniphila [122]. With regard to its effect on intestinal barrier, well-studied examples of eCBs include 2-AG and $\mathrm{N}$-arachidonoylethanolamine (AEA, also called anandamide). In general, AEA contributes to the disruption of the intestinal barrier function, while 2-AG had beneficial effect on the barrier integrity in vivo [122]. 2-AG is a major endogenous agonist of both $\mathrm{CB} 1$ and $\mathrm{CB} 2$ receptors that are involved in intestinal motility, secretion and inflammation [123]. As reviewed by Cani et al. [122], obesity is known to have a greater endocannabinoid system tone, with increased eCBs levels and CB1 activity in the brain, liver, adipose tissue and muscles. Of note, $\mathrm{CB} 1$ knockout mice have been shown to be resistant to dietinduced obesity [122].

Prebiotics treatment of obese mice $(o b / o b)$ reduced gut AEA content and increased the mRNA levels of fatty acid amide hydrolase (FAAH), which degrades several eCBs including AEA, in correlation with low levels of LPS in plasma [124]. In obese mice, 12 days of administration of CB1 receptor antagonist (SR141716A) partially restored the localization of tight junction proteins ZO-1 and occludin and reduced circulating levels of LPS [124]. In contrast, administration of CB1/ CB2 agonist HU-210 in wild-type mice increased gut permeability and exacerbated glucose tolerance [125]. Apical application of AEA and 2-AG exacerbated the EDTA-mediated increase in permeability in Caco-2 cells, although basolateral application enhanced recovery in EDTA-induced permeability [126]. Several studies support the conclusion that 2-AG can counteract murine colitis and systemic inflammation induced by colitis $[127,128]$.

Everard et al. [129] provided an example in which the functions of the innate immune system could influence the gut microbiota and the eCB system. In myeloid differentiation protein 88 (MyD88)- 
knockout mice, the composition of the gut microbiota was altered along with increased levels of anti-inflammatory eCBs, 2-AG and 2-oleoylglycerol (2-OG), and decreased levels of AEA [129]. The oral administration of $A$. muciniphila increased the levels of 2-OG, 2-AG and 2-palmitoylglycerol (2-PG) in the ileum [118]. Binding of 2-OG to GPR119 [130,131], stimulates production of GLP-1 and GLP-2 from intestinal L-cells. GLP-1 stimulates insulin secretion, and GLP2 stabilizes intestinal barrier [113,122]. 2-PG potentiates the antiinflammatory effects of 2-AG [118]

The mechanisms by which colonization of $A$. muciniphila increased expression of 2-OG, 2-AG and 2-PG in the ileum are currently unknown. Given that eCB tone changes over relatively longer time periods, analysis of cause and effect relationship could be challenging. Nonetheless, the findings on A. muciniphila have provided a paradigm that can facilitate future studies.

\section{Perspectives}

As discussed above, several notable findings have improved our understanding about relationship between diet and low-grade endotoxemia and contributed towards development of improved therapeutics. Studies by Liu et al. [84] have shown that different FAs have different effects on cellular morphology. For example, 21 days of consumption of fish oil diet increased jejunal and ileal villus height and the villus height: crypt depth ratio, indicating improved intestinal morphology, relative to the corn oil diet [84]. Considering this, it is intriguing that emulsified FAs shows compromise with the integrity of the intestinal gut barrier. Long chain n-3 PUFAs were by no means safe when it comes to the barrier integrity against the emulsified structure of FAs [80]. For better understandings of biochemical aspects, structural characterization of emulsions of various FAs in the presence of physiological levels of bile acids would be helpful. It could be that micelles with different FAs/LPS compositions leads to differential absorption rates. It would also be interesting to test the TLR4stimulation effects of various chylomicron remnant-like lipoproteins in vitro and in vivo.

Although not discussed here, other interesting clues may be gained from studies related to alkaline phosphatase. The structure of LPS, particularly, regarding the number of phosphate groups impacts the balance in activation of the MyD88 and TRIF (Toll/IL-1 domain-containing adapter inducing IFN- $\beta$ )-dependent pathways, thereby impacting overall inflammatory responses [23]. Alkaline phosphatases can reduce the toxicity of LPS both, in vivo and in vitro through dephosphorylation. Intestinal alkaline phosphatase (IAP) is induced within $2 \mathrm{~h}$ of oral LPS administration [132]. Recently, in a murine dextran sulfate sodium (DSS) model of colitis, administration of resolvin RvE1 resulted in significant improvement of disease activity indices (e.g., body weight, colon length) in an ALP expression dependent manner [133]. Other examples emphasizing the importance of IAP in innate immunity response against microbial LPS or tight junction regulation are shown in Yang et al. [134] and Liu et al. [135]. Reports linking IAP and metabolic states/diseases include Kaliannan et al. [136] and Malo et al. [137].

Given the large among-individual variance of serum levels of intestinal isozyme of ALP, it could be interesting to investigate the abundance of a particular species of bacteria possibly associated with this phenomenon. From the biochemical perspective, it would be interesting to examine whether LPS emulsified by bile acids could better serve as substrates for IAP compared to LPS emulsified by FAs. It is quite possible from the above discussion that the structure of emulsions and/or saturation levels of FAs associated with LPS might exert some influence on the toxicity of LPS by unknown mechanisms. Such effect of structures on the rate of alkaline phosphatase reaction with LPS would thus be of biochemical interest.

After weeks of HFD consumption, the intestinal barrier permeability was increased partly by loosening tight junctions as discussed above. This phenomenon is regulated by several factors including oxidative stress. For example, Deopurkar et al. [138] and Ghanim et al. [139] reported the effectiveness of anti-oxidant vitamin, indicating that oxidative stress is a significant factor in mucosal cells that could cause local inflammation. Such studies convey insights into the tight junctional regulation that enrolls networks of a variety of biochemical reactions, some of which may provide hints for therapeutics.

Another important area not covered in this article is endotoxin tolerance, the state of reduced capacity of the host to respond to LPS activation following a first exposure to this stimulus [140,141]. High dose of E. coli LPS (10-100 ng/ml) robustly upregulates TLR4mediated IL- 6 response $[23,142]$, but this is followed by IL-10 production that represents anti-inflammatory feedback. Importantly, in the case of subclinical levels of LPS $(<10 \mathrm{ng} / \mathrm{ml})$, this second phase is not induced [143]. Other mechanisms for tolerance are likely to involve internalization of TLR4 [144], IRAK-1 phosphorylation [145], expression of SH-2 containing inositol phosphatase [23,143]

Occurrence of endotoxin tolerance has been reported in various immune cells [141]. Endotoxin tolerance dramatically changes the gene expression pattern [141] and may drive macrophages from one that predominantly release proinflammatory mediators amplifying inflammation and damaging host, to one that better kills and presents the antigen [140]. Focus of the current research is on micro RNA genes that coordinate the induction of tolerance in macrophage [146149]. Intriguingly, miR-146a has been shown to mediate induction of protective innate immune tolerance in the neonate intestine [150]. Thus, establishment of intestinal mucosal homeostasis involving colonization of bacterial flora, is likely enabled by appropriate fine tuning and induction of immune tolerance in intestinal epithelial cells [150].

However, further clarification is required as to how HFD-induced phenomena are associated with endotoxin tolerance. It is worthwhile to analyze whether IL- 10 and TGF- $\beta$-dependent induction of tolerance to LPS in human peripheral blood monocytes could be envisaged for intestinal epithelium and WAT macrophages as well [151].

Finally, although this article focused on the pro-inflammatory activity of LPS, Cani et al. have proposed that the eCB system mediates communication between adipose and the gut [122]. Further studies may provide insights into relative significances of LPS and eCB in HFD-induced low-grade systemic inflammation.

\section{References}

1. Hotamisligil GS (2006) Inflammation and metabolic disorders. Nature 444: 860-867. [Crossref]

2. Hubler MJ, Kennedy AJ (2016) Role of lipids in the metabolism and activation of immune cells. J Nutr Biochem 34: 1-7.

3. Stoll LL, Denning GM, Weintraub NL (2004) Potential role of endotoxin as a proinflammatory mediator of atherosclerosis. Arterioscler Thromb Vasc Biol 24: 2227 2236. [Crossref]

4. Khodabandehloo H1, Gorgani-Firuzjaee S1, Panahi G1, Meshkani R2 (2016) Molecular and cellular mechanisms linking inflammation to insulin resistance and $\hat{\mathrm{I}}^{2}$ cell dysfunction. Transl Res 167: 228-256. [Crossref] 
5. Wu H, Tremaroli V, Bäckhed F (2015) Linking Microbiota to Human Diseases: A Systems Biology Perspective. Trends Endocrinol Metab 26: 758-770. [Crossref]

6. West CE, Renz H, Jenmalm MC, Kozyrskyj AL, Allen KJ, et al. (2015) The gut microbiota and inflammatory noncommunicable diseases: associations and potentials for gut microbiota therapies. J Allergy Clin Immunol 135: 3-13. [Crossref]

7. Winer DA, Luck H, Tsai S, Winer S (2016) The Intestinal Immune System in Obesity and Insulin Resistance. Cell Metab 23: 413-426. [Crossref]

8. Kumar H, Kawai T, Akira S (2011) Pathogen recognition by the innate immune system. Int Rev Immunol 30: 16-34. [Crossref]

9. Garrett WS, Gordon JI, Glimcher LH (2010) Homeostasis and inflammation in the intestine. Cell 140: 859-870. [Crossref]

10. Tai N, Wong FS, Wen L (2015) The role of gut microbiota in the development of type 1, type 2 diabetes mellitus and obesity. Rev Endocr Metab Disord 16: 55-65. [Crossref]

11. Graham C, Mullen A, Whelan K (2015) Obesity and the gastrointestinal microbiota: a review of associations and mechanisms. Nutr Rev 73: 376-385. [Crossref]

12. Haque TR, Barritt AS 4th (2016) Intestinal microbiota in liver disease. Best Pract Res Clin Gastroenterol 30: 133-142. [Crossref]

13. Ray K (2012) Gut microbiota: Colorectal cancer-driven by inflammation and gut bacteria? Nat Rev Gastroenterol Hepatol 9: 558. [Crossref]

14. Vogtmann E, Goedert JJ (2016) Epidemiologic studies of the human microbiome and cancer. Br J Cancer 114: 237-242. [Crossref]

15. Brown JM, Hazen SL (2015) The gut microbial endocrine organ: bacterially derived signals driving cardiometabolic diseases. Annu Rev Med 66: 343-359. [Crossref]

16. Mayer EA, Tillisch K, Gupta A (2015) Gut/brain axis and the microbiota. J Clin Invest 125: 926-938. [Crossref]

17. Putignani L, Del Chierico F, Vernocchi P, Cicala M, Cucchiara S, et al. (2016) Gut Microbiota Dysbiosis as Risk and Premorbid Factors of IBD and IBS Along the Childhood-Adulthood Transition. Inflamm Bowel Dis 22: 487-504. [Crossref]

18. Krumbeck JA, Maldonado-Gomez MX, Ramer-Tait AE, Hutkins RW (2016) Prebiotics and synbiotics: dietary strategies for improving gut health. Curr Opin Gastroenterol 32: 110-119. [Crossref]

19. Lackey DE, Olefsky JM (2016) Regulation of metabolism by the innate immune system. Nat Rev Endocrinol 12: 15-28. [Crossref]

20. West CE, Jenmalm MC, Prescott SL (2015) The gut microbiota and its role in the development of allergic disease: a wider perspective. Clin Exp Allergy 45: 43-53. [Crossref]

21. Hammond SM, Claesson A, Jansson AM, Larsson LG, Pring BG, et al. (1987) A new class of synthetic antibacterials acting on lipopolysaccharide biosynthesis. Nature 327 730-732. [Crossref]

22. Schultz H, Weiss JP (2007) The bactericidal/permeability-increasing protein (BPI) in infection and inflammatory disease. Clinica Chimica Acta 384: 12-23. [Crossref]

23. Gnauck A, Lentle RG, Kruger MC (2015) The characteristics and function of bacterial lipopolysaccharides and their endotoxic potential in humans. Int Rev Immunol. [Crossref]

24. Andreasen AS, Krabbe KS, Krogh-Madsen R, Taudorf S, Pedersen BK, et al. (2008) Human endotoxemia as a model of systemic inflammation. Curr Med Chem 15: 16971705. [Crossref]

25. Berg RD (1996) The indigenous gastrointestinal microflora. Trends Microbiol 4: 430435. [Crossref]

26. Cani PD, Bibiloni R, Knauf C, Waget A, Neyrinck AM, et al. (2008) Changes in gut microbiota control metabolic endotoxemia-induced inflammation in high-fat dietinduced obesity and diabetes in mice. Diabetes 57: 1470-1481. [Crossref]

27. Ghoshal S, Witta J, Zhong J, de Villiers W, Eckhardt E (2009) Chylomicrons promote intestinal absorption of lipopolysaccharides. J Lipid Res 50: 90-97. [Crossref]

28. Laugerette F, Vors C, Géloën A, Chauvin MA, Soulage C, et al. (2011) Emulsified lipids increase endotoxemia: possible role in early postprandial low-grade inflammation. $J$ Nutr Biochem 22: 53-59. [Crossref]

29. Novitsky TJ (1998) Limitations of the Limulus amebocyte lysate test in demonstrating circulating lipopolysaccharides. Ann N Y Acad Sci 851: 416-421. [Crossref]

30. Gnauck A, Lentle RG, Kruger MC (2016) Chasing a ghost? - Issues with the determination of circulating levels of endotoxin in human blood. Crit Rev Clin Lab

\section{Sci 53: 197-215. [Crossref]}

31. Gnauck A, Lentle RG, Kruger MC (2015) Aspirin-induced increase in intestinal paracellular permeability does not affect the levels of LPS in venous blood of healthy women. Innate Immun 21: 537-545. [Crossref]

32. Schumann RR (2011) Old and new findings on lipopolysaccharide-binding protein a soluble pattern-recognition molecule. Biochem Soc Trans 39: 989-993. [Crossref]

33. Lamping N, Dettmer R, Schröder NW, Pfeil D, Hallatschek W, et al. (1998) LPSbinding protein protects mice from septic shock caused by LPS or gram-negative bacteria. J Clin Invest 101: 2065-2071. [Crossref]

34. Laugerette F, Furet JP, Debard C, Daira P, Loizon E, et al. (2012) Oil composition of high-fat diet affects metabolic inflammation differently in connection with endotoxin receptors in mice. Am J Physiol Endocrinol Metab 302: E374-386. [Crossref]

35. Hailman E, Lichenstein HS, Wurfel MM, Miller DS, Johnson DA, et al. (1994) Lipopolysaccharide (LPS)-binding protein accelerates the binding of LPS to CD14. J Exp Med 179: 269-277. [Crossref]

36. Wurfel MM, Wright SD (1997) Lipopolysaccharide-binding protein and soluble CD14 transfer lipopolysaccharide to phospholipid bilayers: preferential interaction with particular classes of lipid. J Immunol 158: 3925-3934. [Crossref]

37. Wurfel MM, Hailman E, Wright SD (1995) Soluble CD14 acts as a shuttle in the neutralization of lipopolysaccharide (LPS) by LPS-binding protein and reconstituted high density lipoprotein. J Exp Med 181: 1743-1754. [Crossref]

38. Kitchens RL, Thompson PA (2005) Modulatory effects of sCD14 and LBP on LPS-host cell interactions. J Endotoxin Res 11: 225-229. [Crossref]

39. Umoh FI, Kato I, Ren J, Wachowiak PL, Ruffin MT 4th, et al. (2016) Markers of systemic exposures to products of intestinal bacteria in a dietary intervention study. Eur J Nutr 55: 793-798. [Crossref]

40. Sidahmed E, Cornellier ML, Ren J, Askew LM, Li Y, et al. (2014) Development of exchange lists for Mediterranean and Healthy Eating diets: implementation in an intervention trial. J Hum Nutr Diet 27: 413-425. [Crossref]

41. Cani PD, Amar J, Iglesias MA, Poggi M, Knauf C, et al. (2007) Metabolic endotoxemia initiates obesity and insulin resistance. Diabetes 56: 1761-1772. [Crossref]

42. Erridge C, Attina T, Spickett CM, Webb DJ (2007) A high-fat meal induces low-grade endotoxemia: evidence of a novel mechanism of postprandial inflammation. Am J Clin Nutr 86: 1286-1292. [Crossref]

43. Ghanim H, Abuaysheh S, Sia CL, Korzeniewski K, Chaudhuri A, et al. (2009) Increase in plasma endotoxin concentrations and the expression of Toll-like receptors and suppressor of cytokine signaling-3 in mononuclear cells after a high-fat, highcarbohydrate meal: implications for insulin resistance. Diabetes Care 32: 2281-2287. [Crossref]

44. Pastor Rojo O, López San Román A, Albéniz Arbizu E, de la Hera Martínez A, Ripol Sevillano E, et al. (2007) Serum lipopolysaccharide-binding protein in endotoxemic patients with inflammatory bowel disease. Inflamm Bowel Dis 13: 269-277. [Crossref]

45. Laugerette F, Alligier M, Bastard JP, Drai J, Chanséaume E, et al. (2014) Overfeeding increases postprandial endotoxemia in men: Inflammatory outcome may depend on LPS transporters LBP and sCD14. Mol Nutr Food Res 58: 1513-1518. [Crossref]

46. Tomita M, Ohkubo R, Hayashi M (2004) Lipopolysaccharide transport system across colonic epithelial cells in normal and infective rat. Drug Metab Pharmacokinet 19: 33-40. [Crossref]

47. Mani V, Hollis JH, Gabler NK (2013) Dietary oil composition differentially modulates intestinal endotoxin transport and postprandial endotoxemia. Nutr Metab (Lond) 10: 6. [Crossref]

48. Read TE, Grunfeld C, Kumwenda ZL, Calhoun MC, Kane JP, et al. (1995) Triglyceriderich lipoproteins prevent septic death in rats. J Exp Med 182: 267-272. [Crossref]

49. Vreugdenhil AC, Rousseau CH, Hartung T, Greve JW, van 't Veer C, et al. (2003) Lipopolysaccharide (LPS)-binding protein mediates LPS detoxification by chylomicrons. J Immunol 170: 1399-1405. [Crossref]

50. Beatty WL, Méresse S, Gounon P, Davoust J, Mounier J, et al. (1999) Trafficking of Shigella lipopolysaccharide in polarized intestinal epithelial cells. J Cell Biol 145 689-698. [Crossref]

51. Hornef MW, Frisan T, Vandewalle A, Normark S, Richter-Dahlfors A (2002) Tolllike receptor 4 resides in the Golgi apparatus and colocalizes with internalized lipopolysaccharide in intestinal epithelial cells. J Exp Med 195: 559-570. [Crossref] 
52. Edelblum KL, Turner JR (2009) The tight junction in inflammatory disease: communication breakdown. Curr Opin Pharmacol 9: 715-720. [Crossref]

53. Suzuki T (2013) Regulation of intestinal epithelial permeability by tight junctions. Cell Mol Life Sci 70: 631-659. [Crossref]

54. Bruewer M, Luegering A, Kucharzik T, Parkos CA, Madara JL, et al. (2003) Proinflammatory cytokines disrupt epithelial barrier function by apoptosis-independent mechanisms. J Immunol 171: 6164-6172. [Crossref]

55. Brun P, Castagliuolo I, Di Leo V, Buda A, Pinzani M, et al. (2007) Increased intestinal permeability in obese mice: new evidence in the pathogenesis of nonalcoholic steatohepatitis. Am J Physiol Gastrointest Liver Physiol 292: G518-525. [Crossref]

56. de La Serre CB, Ellis CL, Lee J, Hartman AL, Rutledge JC, et al. (2010) Propensity to high-fat diet-induced obesity in rats is associated with changes in the gut microbiota and gut inflammation. Am J Physiol Gastrointest Liver Physiol 299: G440-448. [Crossref]

57. Guo S, Al-Sadi R, Said HM, Ma TY (2013) Lipopolysaccharide causes an increase in intestinal tight junction permeability in vitro and in vivo by inducing enterocyte membrane expression and localization of TLR-4 and CD14. Am J Pathol 182: 375387. [Crossref]

58. Guo S, Nighot M, Al-Sadi R, Alhmoud T, Nighot P, et al. (2015) Lipopolysaccharide Regulation of Intestinal Tight Junction Permeability Is Mediated by TLR4 Signal Transduction Pathway Activation of FAK and MyD88. J Immunol 195: 4999-5010. [Crossref]

59. Parsons JT (2003) Focal adhesion kinase: the first ten years. J Cell Sci 116: 1409-1416. [Crossref]

60. de Punder K, Pruimboom L (2015) Stress induces endotoxemia and low-grade inflammation by increasing barrier permeability. Front Immunol 6: 223. [Crossref]

61. Furrie E, Macfarlane S, Thomson G, Macfarlane GT; Microbiology \& Gut Biology Group; Tayside Tissue \& Tumour Bank (2005) Toll-like receptors-2, -3 and -4 expression patterns on human colon and their regulation by mucosal-associated bacteria. Immunology 115: 565-574. [Crossref]

62. Lotz M, Gütle D, Walther S, Ménard S, Bogdan C, et al. (2006) Postnatal acquisition of endotoxin tolerance in intestinal epithelial cells. J Exp Med 203: 973-984. [Crossref]

63. Munford RS, Hall CL, Dietschy JM (1981) Binding of Salmonella typhimurium lipopolysaccharides to rat high-density lipoproteins. Infect Immun 34: 835-843. [Crossref]

64. Harris HW, Rockey DC, Chau P (1998) Chylomicrons alter the hepatic distribution and cellular response to endotoxin in rats. Hepatology 27: 1341-1348. [Crossref]

65. Cai L, Ji A, de Beer FC, Tannock LR, van der Westhuyzen DR (2008) SR-BI protects against endotoxemia in mice through its roles in glucocorticoid production and hepatic clearance. J Clin Invest 118: 364-375. [Crossref]

66. Mathison JC, Ulevitch RJ (1979) The clearance, tissue distribution, and cellular localization of intravenously injected lipopolysaccharide in rabbits. J Immunol 123 : 2133-2143. [Crossref]

67. Shao B, Munford RS, Kitchens R, Varley AW (2012) Hepatic uptake and deacylation of the LPS in bloodborne LPS-lipoprotein complexes. Innate Immun 18: 825-833. [Crossref]

68. Deng M, Scott MJ, Loughran P, Gibson G, Sodhi C, et al. (2013) Lipopolysaccharide clearance, bacterial clearance, and systemic inflammatory responses are regulated by cell type-specific functions of TLR4 during sepsis. J Immunol 190: 5152-5160. [Crossref]

69. Mimura Y, Sakisaka S, Harada M, Sata M, Tanikawa K (1995) Role of hepatocytes in direct clearance of lipopolysaccharide in rats. Gastroenterology 109: 1969-1976. [Crossref]

70. Scott MJ, Billiar TR (2008) Beta2-integrin-induced p38 MAPK activation is a key mediator in the CD14/TLR4/MD2-dependent uptake of lipopolysaccharide by hepatocytes. J Biol Chem 283: 29433-29446. [Crossref]

71. Imajo K, Fujita K, Yoneda M, Nozaki Y, Ogawa Y, et al. (2012) Hyperresponsivity to low-dose endotoxin during progression to nonalcoholic steatohepatitis is regulated by leptin-mediated signaling. Cell Metab 16: 44-54. [Crossref]

72. Scott MJ, Liu S, Shapiro RA, Vodovotz Y, Billiar TR (2009) Endotoxin uptake in mouse liver is blocked by endotoxin pretreatment through a suppressor of cytokine signaling-1-dependent mechanism. Hepatology 49: 1695-1708. [Crossref]

73. Ruiz-Núñez B , Dijck-Brouwer DAJ, Muskiet FAJ (2016) The relation of saturated fatty acids with low-grade inflammation and cardiovascular disease. $J$ Nutr Biochem 36: $1-20$
74. Alcock J, Lin HC (2015) Fatty acids from diet and microbiota regulate energy metabolism. F1000Res 4: 738. [Crossref]

75. Kim J, Li Y, Watkins BA (2013) Fat to treat fat: emerging relationship between dietary PUFA, endocannabinoids, and obesity. Prostaglandins Other Lipid Mediat 104-105: 32-41. [Crossref]

76. Banni S, Carta G, Murru E, Cordeddu L, Giordano E, et al. (2011) Krill oil significantly decreases 2-arachidonoylglycerol plasma levels in obese subjects. Nutr Metab (Lond) 8: 7. [Crossref]

77. Rossmeisl M, Jilkova ZM, Kuda O, Jelenik T, Medrikova D, et al. (2012) Metabolic effects of n-3 PUFA as phospholipids are superior to triglycerides in mice fed a high-fat diet: possible role of endocannabinoids. PLoS One 7: e38834. [Crossref]

78. Cano-Cebrián MJ, Zornoza T, Granero L, Polache A (2005) Intestinal absorption enhancement via the paracellular route by fatty acids, chitosans and others: a target for drug delivery. Curr Drug Deliv 2: 9-22. [Crossref]

79. Kvietys PR, Specian RD, Grisham MB, Tso P (1991) Jejunal mucosal injury and restitution: role of hydrolytic products of food digestion. Am J Physiol 261: G384-391. [Crossref]

80. Aspenström-Fagerlund B, Ring L, Aspenström P, Tallkvist J, Ilbäck NG, Glynn AW. (2007) Oleic acid and docosahexaenoic acid cause an increase in the paracellular absorption of hydrophilic compounds in an experimental model of human absorptive enterocytes. Toxicology 237: 12-23. [Crossref]

81. Silen W, Ito S (1985) Mechanisms for rapid re-epithelialization of the gastric mucosal surface. Annu Rev Physiol 47: 217-229. [Crossref]

82. Louis P, Flint HJ (2009) Diversity, metabolism and microbial ecology of butyrateproducing bacteria from the human large intestine. FEMS Microbiol Lett 294: 1-8 [Crossref]

83. Brahe LK, Astrup A, Larsen LH (2013) Is butyrate the link between diet, intestina microbiota and obesity-related metabolic diseases? Obes Rev 14: 950-959. [Crossref]

84. Liu Y, Chen F, Odle J, Lin X, Jacobi SK, et al. (2012) Fish oil enhances intestinal integrity and inhibits TLR4 and NOD2 signaling pathways in weaned pigs after LPS challenge. J Nutr 142: 2017-2024. [Crossref]

85. Lee JY, Ye J, Gao Z, Youn HS, Lee WH, et al. (2003) Reciprocal modulation of Toll-like receptor-4 signaling pathways involving MyD88 and phosphatidylinosito 3-kinase/AKT by saturated and polyunsaturated fatty acids. J Biol Chem 278: 3704137051. [Crossref]

86. Rocha DM, Caldas AP, Oliveira LL, Bressan J, Hermsdorff HH (2016) Saturated fatty acids trigger TLR4-mediated inflammatory response. Atherosclerosis 244: 211-215. [Crossref]

87. Erridge C (2010) Endogenous ligands of TLR2 and TLR4: agonists or assistants? $J$ Leukoc Biol 87: 989-999. [Crossref]

88. Erridge C, Samani NJ (2009) Saturated Fatty Acids Do Not Directly Stimulate TollLike Receptor Signaling. Arterioscler Thromb Vasc Biol 29: 1944-1949. [Crossref]

89. Schaeffler A, Gross P, Buettner R, Bollheimer C, Buechler C, et al. (2009) Fatty acidinduced induction of Toll-like receptor-4/nuclear factor-kappaB pathway in adipocytes links nutritional signalling with innate immunity. Immunology 126: 233-245. [Crossref]

90. Pal D, Dasgupta S, Kundu R, Maitra S, Das G, et al. (2012) Fetuin-A acts as an endogenous ligand of TLR4 to promote lipid-induced insulin resistance. Nat Med 18: 1279-1285. [Crossref]

91. Jialal I, Devaraj S, Adams-Huet B (2016) Plasma fetuin-A does not correlate with monocyte TLR4 in humans. Diabetologia 59: 222-223. [Crossref]

92. Holland WL, Bikman BT, Wang LP, Yuguang G, Sargent KM, et al. (2011) Lipidinduced insulin resistance mediated by the proinflammatory receptor TLR4 requires saturated fatty acid-induced ceramide biosynthesis in mice. J Clin Invest 121: 18581870. [Crossref]

93. Calder PC (2012) Long-chain fatty acids and inflammation. Proc Nutr Soc 71: 284 289. [Crossref]

94. Hirasawa A, Tsumaya K, Awaji T, Katsuma S, Adachi T, et al. (2005) Free fatty acids regulate gut incretin glucagon-like peptide-1 secretion through GPR120. Nat Med 11: 90-94. [Crossref]

95. Oh DY, Talukdar S, Bae EJ, Imamura T, Morinaga H, et al. (2010) GPR120 is an omega-3 fatty acid receptor mediating potent anti-inflammatory and insulin-sensitizing effects. Cell 142: 687-698. [Crossref] 
96. Ichimura A, Hirasawa A, Poulain-Godefroy O, Bonnefond A, Hara T, et al. (2012) Dysfunction of lipid sensor GPR120 leads to obesity in both mouse and human. Nature 483: 350-354. [Crossref]

97. Cintra DE, Ropelle ER, Moraes JC, Pauli JR, Morari J, et al. (2012) Unsaturated fatty acids revert diet-induced hypothalamic inflammation in obesity. PLoS One 7: e30571. [Crossref]

98. Anbazhagan AN, Priyamvada S, Gujral T, Bhattacharyya S, Alrefai WA, et al. (2016) A novel anti-inflammatory role of GPR120 in intestinal epithelial cells. Am J Physiol Cell Physiol 310: C612-621. [Crossref]

99. Bjursell M, Xu X, Admyre T, Böttcher G, Lundin S, et al. (2014) The beneficial effects of $\mathrm{n}-3$ polyunsaturated fatty acids on diet induced obesity and impaired glucose control do not require Gpr120. PLoS One 9:e114942. [Crossref]

100. Marchesi JR, Adams DH, Fava F, Hermes GD, Hirschfield GM, et al. (2016) The gut microbiota and host health: a new clinical frontier. Gut 65: 330-339. [Crossref]

101. Tilg H, Moschen AR (2015) Food, immunity, and the microbiome. Gastroenterology 148: 1107-1119. [Crossref]

102. De Filippo C, Cavalieri D, Di Paola M, Ramazzotti M, Poullet JB, et al. (2010) Impact of diet in shaping gut microbiota revealed by a comparative study in children from Europe and rural Africa. Proc Natl Acad Sci US A 107: 14691-14696. [Crossref]

103. Le Chatelier E, Nielsen T, Qin J, Prifti E, Hildebrand F, et al. (2013) Richness of human gut microbiome correlates with metabolic markers. Nature 500: 541-546. [Crossref]

104. Cotillard A, Kennedy SP, Kong LC, Prifti E, Pons N, et al. (2013) Dietary intervention impact on gut microbial gene richness. Nature 500: 585-588. [Crossref]

105. Hildebrandt MA, Hoffmann C, Sherrill-Mix SA, Keilbaugh SA, Hamady M, et al. (2009) High-fat diet determines the composition of the murine gut microbiome independently of obesity. Gastroenterology 137: 1716-1724. [Crossref]

106. Wu GD, Chen J, Hoffmann C, Bittinger K, Chen YY, et al. (2011) Linking long-term dietary patterns with gut microbial enterotypes. Science 334: 105-108. [Crossref]

107. Remely M, Aumueller E, Jahn D, Hippe B, Brath H, et al. (2014) Microbiota and epigenetic regulation of inflammatory mediators in type 2 diabetes and obesity. Benef Microbes 5: 33-43. [Crossref]

108. de Jonge WJ (2013) The Gut's Little Brain in Control of Intestinal Immunity. ISRN Gastroenterol 2013: 630159. [Crossref]

109. Barreau F, Hugot JP (2014) Intestinal barrier dysfunction triggered by invasive bacteria. Curr Opin Microbiol 17: 91-98. [Crossref]

110. Bäckhed F, Ding H, Wang T, Hooper LV, Koh GY, et al. (2004) The gut microbiota as an environmental factor that regulates fat storage. Proc Natl Acad Sci U S A 101: 15718-15723. [Crossref]

111. Ahrne S, Hagslatt ML (2011) Effect of lactobacilli on paracellular permeability in the gut. Nutrients 3: 104-117. [Crossref]

112. Ait-Belgnaoui A, Durand H, Cartier C, Chaumaz G, Eutamene H, et al. (2012) Prevention of gut leakiness by a probiotic treatment leads to attenuated HPA response to an acute psychological stress in rats. Psychoneuroendocrinology 37: 1885-1895. [Crossref]

113. Cani PD, Possemiers S, Van de Wiele T, Guiot Y, Everard A, et al. (2009) Changes in gut microbiota control inflammation in obese mice through a mechanism involving GLP-2-driven improvement of gut permeability. Gut 58: 1091-1103. [Crossref]

114. Bergmann KR, Liu SX, Tian R, Kushnir A, Turner JR, et al. (2013) Bifidobacteria stabilize claudins at tight junctions and prevent intestinal barrier dysfunction in mouse necrotizing enterocolitis. Am J Pathol 182: 1595-1606. [Crossref]

115. Caesar R, Tremaroli V, Kovatcheva-Datchary P, Cani PD, Bäckhed F (2015) Crosstalk between Gut Microbiota and Dietary Lipids Aggravates WAT Inflammation through TLR Signaling. Cell Metab 22: 658-668. [Crossref]

116. Turnbaugh PJ, Hamady M, Yatsunenko T, Cantarel BL, Duncan A, et al. (2009) A core gut microbiome in obese and lean twins. Nature 457: 480-484. [Crossref]

117. Derrien M, Vaughan EE, Plugge CM, de Vos WM (2004) Akkermansia muciniphila gen. nov., sp. nov., a human intestinal mucin-degrading bacterium. Int J Syst Evol Microbiol 54: 1469-1476. [Crossref]

118. Everard A, Belzer C, Geurts L, Ouwerkerk JP, Druart C, et al. (2013) Cross-talk between Akkermansia muciniphila and intestinal epithelium controls diet-induced obesity. Proc Natl Acad Sci U S A 110: 9066-9071. [Crossref]
119. Schneeberger M, Everard A, Gómez-Valadés AG, Matamoros S, Ramírez S, et al (2015) Akkermansia muciniphila inversely correlates with the onset of inflammation, altered adipose tissue metabolism and metabolic disorders during obesity in mice. Sci Rep 5: 16643.

120. David LA, Maurice CF, Carmody RN, Gootenberg DB, Button JE, et al. (2014) Diet rapidly and reproducibly alters the human gut microbiome. Nature 505: 559-563. [Crossref]

121. Matias I, Gonthier MP, Orlando P, Martiadis V, De Petrocellis L, et al. (2006) Regulation, function, and dysregulation of endocannabinoids in models of adipose and beta-pancreatic cells and in obesity and hyperglycemia. J Clin Endocrinol Metab 91: 3171-3180. [Crossref]

122. Cani PD, Plovier H, Van Hul M, Geurts L, Delzenne NM, et al. (2016) Endocannabinoids - at the crossroads between the gut microbiota and host metabolism. Nat Rev Endocrinol 12: 133-143. [Crossref]

123. Storr MA, Keenan CM, Emmerdinger D, Zhang H, Yüce B, et al. (2008) Targeting endocannabinoid degradation protects against experimental colitis in mice: involvement of CB1 and CB2 receptors. J Mol Med (Berl) 86: 925-936. [Crossref]

124. Muccioli GG, Naslain D, Bäckhed F, Reigstad CS, Lambert DM, et al. (2010) The endocannabinoid system links gut microbiota to adipogenesis. Mol Syst Biol 6: 392. [Crossref]

125. Geurts L, Muccioli GG, Delzenne NM, Cani PD (2013) Chronic endocannabinoid system stimulation induces muscle macrophage and lipid accumulation in type 2 diabetic mice independently of metabolic endotoxaemia. PLoS One 8: e55963. [Crossref]

126. Alhamoruni A, Lee AC, Wright KL, Larvin M, O’Sullivan SE (2010) Pharmacological effects of cannabinoids on the Caco-2 cell culture model of intestinal permeability. $J$ Pharmacol Exp Ther 335: 92-102. [Crossref]

127. Storr MA, Keenan CM, Zhang H, Patel KD, Makriyannis A, et al. (2009) Activation of the cannabinoid 2 receptor (CB2) protects against experimental colitis. Inflamm Bowel Dis 15: 1678-1685. [Crossref]

128. Engel MA, Kellermann CA, Burnat G, Hahn EG, Rau T, et al. (2010) Mice lacking cannabinoid CB1-, CB2-receptors or both receptors show increased susceptibility to trinitrobenzene sulfonic acid (TNBS)-induced colitis. J Physiol Pharmacol 61: 89-97. [Crossref]

129. Everard A, Geurts L, Caesar R, Van Hul M, Matamoros S, et al. (2014) Intestinal epithelial MyD88 is a sensor switching host metabolism towards obesity according to nutritional status. Nat Commun 5: 5648

130. Hansen KB, Rosenkilde MM, Knop FK, Wellner N, Diep TA, et al. (2011) 2-Oleoyl glycerol is a GPR 119 agonist and signals GLP-1 release in humans. J Clin Endocrino Metab 96: E1409-1417. [Crossref]

131. Syed SK, Bui HH, Beavers LS, Farb TB, Ficorilli J, et al. (2012) Regulation of GPR119 receptor activity with endocannabinoid-like lipids. Am J Physiol Endocrinol Metab 303: E1469-1478. [Crossref]

132. Koyama I, Matsunaga T, Harada T, Hokari S, Komoda T (2002) Alkaline phosphatases reduce toxicity of lipopolysaccharides in vivo and in vitro through dephosphorylation. Clin Biochem 35: 455-461. [Crossref]

133. Campbell EL, MacManus CF, Kominsky DJ, Keely S, Glover LE, et al. (2010) Resolvin E1-induced intestinal alkaline phosphatase promotes resolution of inflammation through LPS detoxification. Proc Natl Acad Sci U S A 107: 1429814303. [Crossref]

134. Yang Y, Millán JL, Mecsas J, Guillemin K (2015) Intestinal alkaline phosphatase deficiency leads to lipopolysaccharide desensitization and faster weight gain. Infect Immun 83: 247-258. [Crossref]

135. Liu W, Hu D, Huo H, Zhang W, Adiliaghdam F, et al. (2015) Intestinal Alkaline Phosphatase Regulates Tight Junction Protein Levels. J Am Coll Surg S10727515(15)01776-01777. [Crossref]

136. Kaliannan K, Hamarneh SR, Economopoulos KP, Nasrin Alam S, Moaven O, et al (2013) Intestinal alkaline phosphatase prevents metabolic syndrome in mice. Proc Natl Acad Sci U SA 110: 7003-7008. [Crossref]

137. Malo MS (2015) A High Level of Intestinal Alkaline Phosphatase Is Protective Against Type 2 Diabetes Mellitus Irrespective of Obesity. EBioMedicine 2: 20162023. [Crossref]

138. Deopurkar R, Ghanim H, Friedman J, Abuaysheh S, Sia CL, et al. (2010) Differentia effects of cream, glucose, and orange juice on inflammation, endotoxin, and the 
expression of Toll-like receptor-4 and suppressor of cytokine signaling-3. Diabetes Care 33: 991-997. [Crossref]

139. Ghanim H, Sia CL, Upadhyay M, Korzeniewski K, Viswanathan P, et al. (2010) Orange juice neutralizes the proinflammatory effect of a high-fat, high-carbohydrate meal and prevents endotoxin increase and Toll-like receptor expression. Am J Clin Nutr 91: 940-949. [Crossref]

140. de Lima TM, Sampaio SC, Petroni R, Brigatte P, Velasco IT, et al. (2014) Phagocytic activity of LPS tolerant macrophages. Mol Immunol 60: 8-13. [Crossref]

141. Biswas SK, Lopez-Collazo E (2009) Endotoxin tolerance: new mechanisms, molecules and clinical significance. Trends Immunol 30: 475-487. [Crossref]

142. Shnyra A, Brewington R, Alipio A, Amura C, Morrison DC (1998) Reprogramming of lipopolysaccharide-primed macrophages is controlled by a counterbalanced production of IL-10 and IL-12. J Immunol 160: 3729-3736. [Crossref]

143. Maitra U, Deng H, Glaros T, Baker B, Capelluto DG, et al. (2012) Molecular mechanisms responsible for the selective and low-grade induction of proinflammatory mediators in murine macrophages by lipopolysaccharide. J Immunol 18: 1014-1023. [Crossref]

144. Forestier C, Moreno E, Pizarro-Cerda J, Gorvel JP (1999) Lysosomal accumulation and recycling of lipopolysaccharide to the cell surface of murine macrophages, an in vitro and in vivo study. J Immunol 162: 6784-6791. [Crossref]
145. Medvedev AE, Lentschat A, Wahl LM, Golenbock DT, Vogel SN (2002) Dysregulation of LPS-induced Toll-like receptor 4-MyD88 complex formation and IL-1 receptorassociated kinase 1 activation in endotoxin-tolerant cells. J Immunol 169: 5209-5216. [Crossref]

146. El Gazzar M, McCall CE (2010) MicroRNAs distinguish translational from transcriptional silencing during endotoxin tolerance. J Biol Chem 285: 20940-20951. [Crossref]

147. Liu Y1, Chen Q, Song Y, Lai L, Wang J, et al. (2011) MicroRNA-98 negatively regulates IL-10 production and endotoxin tolerance in macrophages after LPS stimulation. FEBS Lett 585: 1963-1968. [Crossref]

148. Doxaki C, Kampranis SC, Eliopoulos AG, Spilianakis C, Tsatsanis C (2015) Coordinated Regulation of miR-155 and miR-146a Genes during Induction of Endotoxin Tolerance in Macrophages. J Immunol 195: 5750-5761. [Crossref]

149. O’Neill LA, Sheedy FJ, McCoy CE (2011) MicroRNAs: the fine-tuners of Toll-like receptor signalling. Nat Rev Immunol 11: 163-175. [Crossref]

150. Chassin C, Kocur M, Pott J, Duerr CU, Gütle D, et al. (2010) miR-146a mediates protective innate immune tolerance in the neonate intestine. Cell Host Microbe 8 358-368. [Crossref]

151. Randow F, Syrbe U, Meisel C, Krausch D, Zuckermann H, et al. (1995) Mechanism of endotoxin desensitization: involvement of interleukin 10 and transforming growth factor beta. J Exp Med 181: 1887-1892. [Crossref]

Copyright: (C2016 Nishizawa K. This is an open-access article distributed under the terms of the Creative Commons Attribution License, which permits unrestricted use, distribution, and reproduction in any medium, provided the original author and source are credited. 